\title{
Macrothelypteris e Thelypteris subg. Cyclosorus (Thelypteridaceae) da Estação Ecológica do Panga, Uberlândia, Minas Gerais, Brasil
}

\author{
ADRIANA A. ARANTES ${ }^{1}$, JEFFERSON PRADO ${ }^{2}$ e MARLI A. RANAL ${ }^{1}$
}

(recebido: 19 de dezembro de 2006; aceito: 29 de junho de 2007)

\begin{abstract}
Macrothelypteris and Thelypteris subg. Cyclosorus (Thelypteridaceae) of "Estação Ecológica do Panga", Uberlândia, Minas Gerais, Brazil). A floristic survey of pteridophytes of "Estação Ecológica do Panga" has been carried out since 1986. This Ecological Station covers an area of 409.5 hectares between the geographical coordinates $19^{\circ} 09^{\prime} 20^{\prime \prime}-19^{\circ} 11^{\prime} 10^{\prime \prime} \mathrm{S}$ and $48^{\circ} 23^{\prime} 20^{\prime \prime}-$ $48^{\circ} 24^{\prime} 35^{\prime \prime} \mathrm{W}$, it is situated about $30 \mathrm{~km}$ South of Uberlândia, at 740-840 $\mathrm{m}$ in elevation. This area is considered representative of the natural remnant vegetation of the region, being covered by different savannah physiognomies from open grassland to dense woodlands and forest formations. In this survey, 52 species of pteridophytes were found, 14 of them belonging to Macrothelypteris and Thelypteris genera (Thelypteridaceae). The species of Thelypteris are including in four subgenera (Amauropelta, Goniopteris, Cyclosorus, and Meniscium). Putative hybrid specimens between Thelypteris dentata (Forssk.) E. St. John and T. hispidula (Decne.) C. F. Reed were also recorded. The collected specimens are deposited in the herbaria HUFU, SP, and UC. The taxonomic treatment for the species of the genera Macrothelypteris and Thelypteris subg. Cyclosorus recorded in the area is presented. Field observations showed that the group occurs mostly in gallery forest and wetlands in the Panga area. Some species of subgenus Cyclosorus have showed large morphological variation in the study area. Keys for genera, subgenera and species are also presented.
\end{abstract}

Key words - Cyclosorus, Macrothelypteris, Pteridophyta, savannah, Thelypteridaceae

RESUMO - (Macrothelypteris e Thelypteris subg. Cyclosorus (Thelypteridaceae) da Estação Ecológica do Panga, Uberlândia, Minas Gerais, Brasil). O levantamento florístico das pteridófitas da "Estação Ecológica do Panga" vem sendo realizado desde 1986. A área abrange 409,5 ha e está situada ca. $30 \mathrm{~km}$ ao sul da cidade de Uberlândia, entre as coordenadas $19^{\circ} 09^{\prime} 20^{\prime \prime}-19^{\circ} 11^{\prime} 10^{\prime \prime} \mathrm{S}$ e $48^{\circ} 23^{\prime} 20^{\prime \prime}-48^{\circ} 24^{\prime} 35^{\prime \prime}$ W, a 740-840 m de altitude. Esta área é considerada representativa de remanescentes de vegetação natural da região, apresentando diferentes fisionomias campestres, savânicas e florestais. Neste levantamento foram encontradas 52 espécies de pteridófitas, sendo 14 delas pertencentes aos gêneros Macrothelypteris e Thelypteris (Thelypteridaceae). As espécies de Thelypteris pertencem a quatro subgêneros (Amauropelta, Goniopteris, Cyclosorus e Meniscium). Prováveis espécimes híbridos entre Thelypteris dentata (Forssk.) E. St. John e T. hispidula (Decne.) C. F. Reed também foram registrados. Os espécimestestemunho estão depositados nos Herbários HUFU, SP e UC. O tratamento taxonômico das espécies dos gêneros Macrothelypteris e Thelypteris subg. Cyclosorus coletados na área de estudo é apresentado. As observações de campo mostraram que a maioria das espécies ocorre nas matas de galeria e nos campos úmidos do Panga. Algumas espécies do subgênero Cyclosorus apresentam grande variação morfológica na área estudada. Também são apresentadas chaves de identificação para gêneros, subgêneros e espécies.

Palavras-chave - Cerrado, Cyclosorus, Macrothelypteris, Pteridophyta, Thelypteridaceae

\section{Introdução}

Thelypteridaceae é uma das famílias mais ricas de pteridófitas, com cerca de 1.000 espécies, de distribuição subcosmopolita, com a maioria das espécies ocorrendo nas regiões tropical e subtropical (Ponce 1995, Smith \& Cranfill 2002). A família geralmente é reconhecida como um grupo monofilético (Smith 1990, Smith \& Cranfill 2002). Recentemente, Smith \& Cranfill (2002) comprovaram a existência de relações filogenéticas entre

\footnotetext{
1. Universidade Federal de Uberlândia, Instituto de Biologia, Caixa Postal 593, 38400-902 Uberlândia, MG, Brasil.

2. Instituto de Botânica, Caixa Postal 3005, 01061-970 São Paulo, SP, Brasil.

Autor para correspondência: adrianaa@umuarama.ufu.br
}

Thelypteridaceae e o grupo formado pelas samambaias atirióides, blecnóides, onocleóides e pelas samambaias arborescentes. Este estudo ainda precisa de maiores confirmações, mas até o momento se sabe que a família possui duas linhagens principais, uma formada pelo grupo fegopteróide, incluindo Phegopteris, Pseudophegopteris e Macrothelypteris, e outra pelo grupo telipteróide, incluindo o gênero Thelypteris com seus subgêneros Amauropelta (Kunze) A. R. Sm., Cyclosorus s.l., Goniopteris (C. Presl) Duek, Meniscium (Schreber) C. F. Reed e Steiropteris (C. Chr.) Iwats., entre os que ocorrem no Brasil.

A circunscrição dos gêneros nesta família é controversa e dependente da classificação adotada. Há uma tendência do reconhecimento de apenas dois gêneros, Macrothelypteris, com suas espécies nativas 
dos trópicos e subtrópicos da Ásia, Ilhas do Pacífico, Austrália (Queensland) e Havaí (Mickel \& Smith 2004), e Thelypteris, subcosmopolita e subdividido em vários subgêneros. Adotando-se o mesmo arranjo taxonômico proposto por Smith (1992), cinco subgêneros de Thelypteris ocorrem no Brasil, Amauropelta, Cyclosorus, Goniopteris, Meniscium e Steiropteris.

Subgêneros paleotropicais e neotropicais foram revisados e monografados (Maxon \& Morton 1938, Smith 1971). No Brasil, não há tratamentos recentes para a família como um todo, desde o trabalho de Baker (1870) para a Flora Brasiliensis. Thelypteridaceae no Brasil tem sido tratada em floras regionais como a de Santa Catarina (Sehnem 1979), do Brasil Austral (Ponce 1995) e do Estado de São Paulo (Salino \& Semir 2002, 2004a, b).

O levantamento florístico das pteridófitas da Estação Ecológica do Panga vem sendo realizado desde 1986, um ano após a aquisição da área pela Universidade Federal de Uberlândia. Hoje, a Estação Ecológica do Panga (E.E. Panga) é uma das poucas formações de vegetação natural da região. Em função do seu estado de preservação e dos diversos trabalhos que estão sendo realizados, incluindo florística, fitossociologia e dinâmica de populações, a área atualmente é considerada de alta importância biológica (Drummond et al. 2005). Observações ecológicas mostram uma grande representatividade de Thelypteridaceae na área (Ranal 2003, 2004, Araújo et al. 2002), se comparadas com as angiospermas. Por exemplo, a família Thelypteridaceae está entre as mais ricas do estrato herbáceo, alcançando a quarta posição em riqueza de espécies (11 espécies) em um estudo sobre o estrato herbáceo-arbustivo de um gradiente florestal do Panga (Arantes 2002).

O presente trabalho apresenta parte do tratamento de Thelypteridaceae para a Estação Ecológica do Panga, Uberlândia, MG, abordando as espécies dos gêneros Macrothelypteris e Thelypteris subg. Cyclosorus. As espécies de Thelypteris dos subgêneros Goniopteris e Meniscium foram tratadas em Arantes et al. (2007).

\section{Material e métodos}

A Estação Ecológica do Panga abrange 409,5 ha e está situada $30 \mathrm{~km}$ ao sul do centro da cidade de Uberlândia, MG, entre as coordenadas de $19^{\circ} 09^{\prime} 20^{\prime \prime}-19^{\circ} 11^{\prime} 10^{\prime \prime} \mathrm{S}$ e $48^{\circ} 23^{\prime} 20^{\prime \prime}$ $48^{\circ} 24^{\prime} 35^{\prime \prime}$ W, a 740-840 m de altitude (Araújo et al. 2002). A área apresenta fisionomias comuns do bioma Cerrado como campestres (campo úmido e veredas), savânicas (campo sujo, campo cerrado, cerrado s.s.) e florestais (cerradão, mata mesófila semidecídua de encosta e de galeria) (Schiavini \& Araújo 1989, Cardoso \& Schiavini 2002, Ranal 2003).
Os espécimes testemunhos foram coletados, herborizados e depositados nos Herbários HUFU (Universidade Federal de Uberlândia, MG), SP (Instituto de Botânica, SP) e UC (University Herbarium, Berkeley, CA, E.U.A). As descrições foram elaboradas com base nos caracteres morfológicos dos espécimes coletados na área e, quando necessário, complementadas com material de áreas próximas. As descrições da família, gêneros e subgêneros foram baseadas nos trabalhos de Smith $(1971,1992)$ e Mickel \& Smith (2004). Abreviaturas dos autores de espécies seguem Pichi-Sermolli(1996).

\section{Resultados e Discussão}

Thelypteridaceae Pic.Serm., Webbia 24:711. 1970. Tipo: Thelypteris Schmidel.

Plantas terrestres, raramente epífitas ou rupícolas. Rizoma reptante, ereto ou decumbente, robusto a delicado, glabro ou geralmente revestido por escamas pubescentes ou glabras. Frondes desenvolvidas, com vernação circinada nos brotos, monomorfas ou subdimorfas (as férteis apresentando segmentos das pinas menores que os das frondes estéreis), raro dimorfas, fasciculadas ou espaçadas; pecíolos não articulados com o rizoma, com dois feixes vasculares em forma de meia lua na base, unindo-se e formando um feixe em forma de U na porção distal; lâminas simples a 1-pinadas ou 1-pinado-pinatífidas, raro 2 ou 3-pinado-pinatífidas; indumento com tricomas unicelulares, simples, setosos, furcados ou estrelados, glandulares, e ainda setiformes pluricelulares, escamas presentes na base do pecíolo, raque e costa; nervuras livres a completamente anastomosadas, aréolas sem vênulas ou com uma vênula excurrente. Soros sobre as nervuras, na face abaxial da lâmina, arredondados, ocasionalmente oblongos ou alongados, às vezes arqueados na junção das nervuras transversais, muito raramente com esporângios acrosticóides; paráfises presentes ou não; indúsio desenvolvido, glabro ou piloso, circular-reniforme, pequeno e espatulado ou ainda ausente; pedicelo do esporângio formado por três fileiras de células, glabro ou setoso, ânulo vertical, interrompido pelo pedicelo; esporos bilaterais, monoletes, superfície reticulada, freqüentemente perfurada ou variavelmente verrugosa a papilosa ou espinhosa. $x=27,29-36$.

A família tem distribuição subcosmopolita, com a maioria das espécies ocorrendo nas regiões tropicais e subtropicais (Smith 1992).

Os principais caracteres da família são a presença de dois feixes vasculares em forma de meia lua na base do pecíolo, soros abaxiais, arredondados e sobre as nervuras, esporos bilaterais com perispório espesso e o número base de cromossomos. Para a caracterização dos subgêneros de Thelypteris são utilizados principalmente o tipo de 
indumento, forma das lâminas, padrão de venação e o número básico de cromossomos, que é constante em cada subgênero (Amauropelta $\mathrm{x}=29$, Cyclosorus $\mathrm{x}=36$, Goniopteris $\mathrm{x}=36$, Meniscium $\mathrm{x}=36$ e para o gênero Macrothelypteris $\mathrm{x}=31$ (Mickel \& Smith 2004)).

Após 20 anos de coletas sistemáticas, Thelypteridaceae revelou-se uma das famílias mais diversas do Panga. Foram encontrados dois gêneros, Macrothelypteris e Thelypteris, este último representado por quatro subgêneros (Amauropelta, Goniopteris, Cyclosorus e Meniscium), totalizando 14 espécies e um possível híbrido entre Thelypteris dentata e T. hispidula.

Macrothelypteris está representado por apenas uma espécie, Macrothelypteris torresiana (Gaudich.) Ching, e Thelypteris subg. Cyclosorus por quatro espécies, T. conspersa (Schrad.) A. R. Sm., T. dentata (Forssk.) E. St. John, T. hispidula (Decne.) C. F. Reed e T. interrupta (Willd.) K. Iwats.

Chave para os gêneros de Thelypteridaceae da Estação Ecológica do Panga

1. Frondes 2-pinado-pinatífidas

I. Macrothelypteris

1. Frondes 1-pinado-pinatífidas ou 1-pinadas

II. Thelypteris

I. Macrothelypteris (H. Itô) Ching, Acta Phytotax. Sin. 8:308. 1963. $\equiv$ Thelypteris sect. Macrothelypteris $\mathrm{H}$. Itô in Nakai \& Honda, Nov. Fl. Jap. 4:141. 1939. $\equiv$ Thelypteris subg. Macrothelypteris (H. Itô) A. R. Sm., Phytologia 34:233. 1976. Tipo: Thelypteris torresiana (Gaudich.) Alston [三Polystichum torresianum Gaudich.] $\equiv$ Macrothelypteris torresiana (Gaudich.) Ching.

Plantas terrestres, rizoma curto-reptante, com ápice coberto por escamas linear-lanceoladas, pilosas. Frondes monomorfas; lâminas 2-pinado-pinatífidas, com pinas proximais não reduzidas, ápice gradualmente reduzido; pecíolo e raque sulcados adaxialmente; aeróforos e gemas ausentes; raque abaxialmente sem escamas; pinas 1pinado-pinatífidas, sésseis ou curto-pecioluladas; nervuras livres, 1-furcadas ou normalmente bifurcadas e terminando antes da margem dos segmentos; indumento com tricomas unicelulares e pluricelulares, simples, longo-septados e glandulares. Soros arredondados, sobre as nervuras, medianos; indúsio pequeno, pouco visível nos soros maduros; cápsula dos esporângios com uma pequena glândula capitada; esporos com perispório alado e reticulado.

Macrothelypteris assemelha-se a alguns gêneros do grupo driopteróide como Ctenitis, Megalastrum e Lastreopsis. Entretanto, com base em caracteres morfológicos como a presença de tricomas aciculares, pecíolo com dois feixes vasculares em forma de meia lua na base e o baixo número de cromossomos, este gênero foi reposicionado em Thelypteridaceae (Smith 1992, 1995).

O gênero compreende nove espécies das regiões tropicais e subtropicais do Velho Mundo, da África a Queensland (Austrália) e Havaí (Mickel \& Smith 2004); apenas Macrothelypteris torresiana é amplamente naturalizada no neotrópico. Estudos moleculares recentes (Smith \& Cranfill 2002) demonstraram que Macrothelypteris, Phegopteris e Pseudophegopteris formam o clado mais basal da família, sendo o grupo irmão de todos os outros gêneros e espécies de Thelypteridaceae.

Macrothelypteris torresiana (Gaudich.) Ching, Acta Phytotax. Sinica 8:310. 1963. $\equiv$ Polystichum torresianum Gaudich. In Freycinet, Voy. Uranie:333. 1828. Thelypteris torresiana (Gaudich.) Alston, Lilloa 30:111. 1960. Tipo: MARIANA ISLANDS: Gaudichaud s.n. (holótipo P, n.v.).

= Aspidium uliginosum Kunze, Linnaea 20:6. 1847. $\equiv$ Dryopteris uliginosa (Kunze) C. Chr., Index fil., Suppl. 3:100. 1934. Thelypteris uliginosa (Kunze) Ching, Bull. Fan. Mem. Inst. Biol. 6:342. 1936. Lectótipo (designado por Morton, Contr. U.S. Natl. Herb. 38: 219. 1973): Cult. Hort. Bot. Leipzig, origem Java (BR, foto US, n.v.).

Rizoma curto-reptante, $1,5-2 \mathrm{~cm}$ diâm., revestido no ápice por escamas linear-lanceoladas, castanhas, brilhantes, 3-8 mm compr. Frondes 50-100 cm compr.; pecíolos 16-44 x 0,4-0,8 cm, castanho-esverdeados, brilhantes, revestidos na base por escamas similares às do rizoma, glabros na porção distal; raque castanhoesverdeada, brilhante; pinas deltóides, 1-pinadopinatífidas, $12-22 \mathrm{~cm}$ compr., sésseis ou pecioluladas, peciólulo 0,4-0,8 cm; pínulas pinatífidas ou crenadas; nervuras livres, comumente furcadas, terminando antes da margem dos segmentos; indumento abaxial formado por tricomas longo-septados, dispostos espaçadamente sobre costa e cóstula, 1-1,5 mm compr., adaxialmente tricomas simples, aciculares sobre raque, costa e cóstula, 0,2-0,3 mm compr.; lâmina entre as nervuras com tricomas glandulares, amarelados. Soros medianos, arredondados; indúsio pequeno, pouco visível na maturidade do esporângio, com tricomas setiformes; esporângio com tricomas capitados próximos ao ânulo.

Material examinado: BRASIL. Minas Gerais: Uberlândia, Estação Ecológica do Panga, VIII-1995, 
M.A. Ranal 607 (HUFU, SP); IV-1999, M.A. Ranal 652 (HUFU), 669 (HUFU), 678 (HUFU);VII-1999, M.A. Ranal 761 (HUFU); 772 (HUFU), 778 (HUFU), 779 (HUFU), 780 (HUFU), 785 (HUFU); X-1999, M.A. Ranal 866 (HUFU), 876 (HUFU), 878 (HUFU), 883 (HUFU), 894 (HUFU), 912 (HUFU); XI-1999, M.A. Ranal 918 (HUFU), 960 (HUFU); XII/2000, M.A. Ranal 1079 (HUFU), 1093 (HUFU).

Esta espécie é a única representante da família na área de estudo com frondes 2-pinado-pinatífidas.

Assim como Thelypteris dentata, Macrothelypteris torresiana foi introduzida das regiões tropicais e subtropicais do Velho Mundo (África, Ásia e Ilhas Pacíficas), e hoje se encontra amplamente naturalizada no Novo Mundo, ocorrendo desde o sudeste dos Estados Unidos até o nordeste da Argentina e Paraguai (Ponce 1987, Smith 1992).

Macrothelypteris torresiana é uma planta terrestre muito comum ao longo de barrancos úmidos, margem de estradas, trilhas e terrenos baldios. Na E. E. do Panga ocorre principalmente nas áreas de mata galeria, onde é capaz de formar banco de esporos (Ranal 2003, 2004).

Thelypteris Schmidel, Icon. Pl. (ed. Keller):45, tab.II. 1763. nom. Cons. Tipo: Thelypteris palustris Schott [三 Acrostichum thelypteris L.].

Plantas terrestres, raramente epífitas ou rupícolas. Rizoma longo-reptante a curto-reptante ou ereto; escamas do rizoma inteiras e comumente ciliadas na margem e/ ou superfície. Frondes monomorfas, subdimorfas ou dimorfas, simples a 1-pinadas, mais frequientemente 1pinado-pinatífidas; pecíolo, raque e costa adaxialmente sulcados; lâminas com pinas proximais reduzidas ou não, ápice gradualmente reduzido ou não, raro abruptamente reduzido; aeróforos e gemas presentes em alguns subgêneros; raque com ou sem escamas; pinas inteiras, lobadas a profundamente pinatífidas (pinatissectas), sésseis ou curto-pecioluladas; nervuras livres, geralmente simples, raro 1-furcadas, atingindo a margem dos segmentos ou regularmente anastomosadas; indumento variável desde tricomas unicelulares ou pluricelulares, simples, ramificados, septados ou não, aciculares, furcados, setosos ou capitados glandulares, dispostos densa ou espaçadamente sobre os tecidos entre as nervuras. Soros arredondados, oblongos, lineares ou elípticos, sobre as nervuras, infra a supramedianos; indúsio presente ou não, quando presente geralmente reniforme; esporângios glabros, ocasionalmente setosos ou com tricomas glandulares no pedicelo; esporos bilaterais, com perispório desenvolvido.

Alguns caracteres distintivos deste gênero são dois feixes vasculares presentes no pecíolo, diferentemente das samambaias driopteróides que possuem vários feixes; tricomas aciculares em várias partes das frondes, esporos bilaterais com perispório desenvolvido, e baixo número de cromossomos $(\mathrm{x}=27-36)$, se comparado com as driopteróides e atirióides, que variam de $\mathrm{x}=40$, 41 , respectivamente (figuras 1-8).

Thelypteris é um gênero com distribuição subcosmopolita, com cerca de 875 espécies, das quais aproximadamente 300 ocorrem na região neotropical (Smith 1990, 1992, 1995, Mickel \& Smith 2004). No Brasil ocorrem pelo menos 84 espécies (Salino \& Semir 2002), das quais 65 são encontradas nas regiões Sudeste e Sul do País, sendo 26 espécies do subgênero Amauropelta, 18 de Goniopteris, sete de Cyclosorus, sete de Meniscium, cinco de Steiropteris e duas espécies pouco conhecidas e com posição taxonômica incerta (Salino \& Semir 2003).

Chave para os subgêneros de Thelypteris da Estação Ecológica do Panga

1. Frondes 1-pinadas; pinas com margens inteiras, onduladas ou serreadas; nervuras anastomosadas Subg. Meniscium

1. Frondes 1-pinado-pinatífidas; pinas pinatífidas ou pinatilobadas; nervuras livres ou unidas abaixo do sinus

2. Indumento com tricomas bifurcados e/ou estrelados sobre a raque, costa e ápice das escamas do rizoma Subg. Goniopteris

2. Indumento com tricomas simples, unicelulares ou pluricelulares sobre a raque, costa e ápice das escamas do rizoma

3. Lâmina com vários pares de pinas proximais reduzidas (mais de 3), as mais basais auriculadas; nervuras livres ou unindo-se abaixo ou junto ao sinus

Subg. Amauropelta

3. Lâmina sem pinas proximais reduzidas ou, se presentes, no máximo de 1-3 pares;

nervuras terminando nos sinus ou unindo-se abaixo deles formando uma vênula

excurrente

Subg. Cyclosorus 

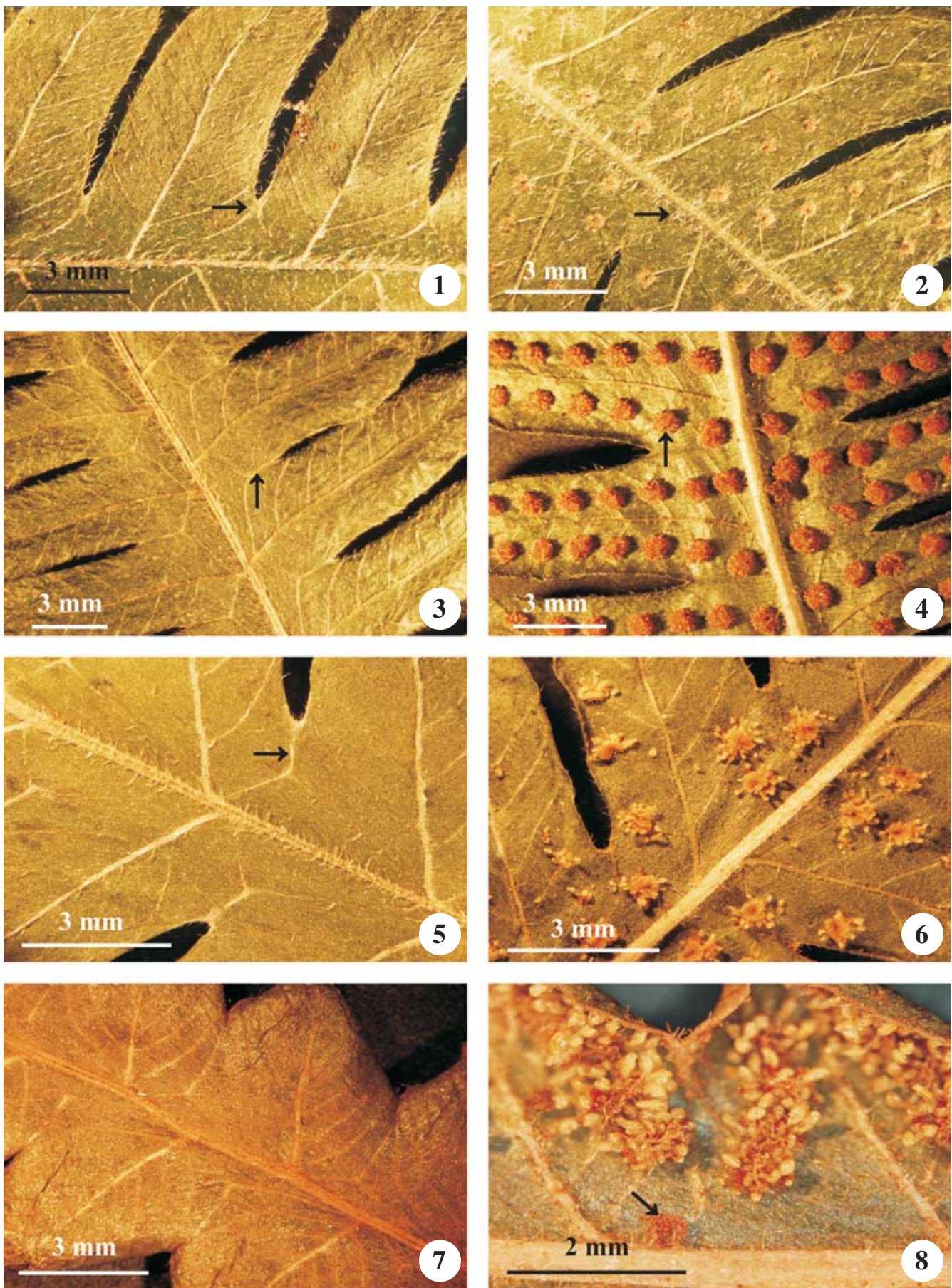

Figuras 1-2. Thelypteris conspersa (Schrad.) A. R. Sm. 1. Face adaxial da lâmina. 2. Face abaxial da lâmina mostrando os soros. 3-4. Thelypteris dentata (Forssk.) E. P. St. John. 3. Face adaxial da lâmina. 4. Face abaxial da lâmina mostrando os soros. 5-6. Thelypteris hispidula (Desne) C. F. Reed. 5. Face adaxial da lâmina. 6. Face abaxial da lâmina mostrando os soros. 7-8. Thelypteris interrupta (Willd.) K. Iwats. 7. Face adaxial da lâmina. 8. Face abaxial da lâmina mostrando os soros. (1-2: Ranal 1267, 3-4: Arantes \& Ranal 1406, 5-6: Ranal 948, 7-8: Ranal 981).

Figuras 1-2. Thelypteris conspersa (Schrad.) A. R. Sm. 1. Lamina adaxial surface. 2. Lamina abaxial surface showing the sori. 34. Thelypteris dentata (Forssk.) E. P. St. John. 3. Lamina adaxial surface. 4. Lamina abaxial surface showing the sori. 5-6. Thelypteris hispidula (Desne) C. F. Reed. 5. Lamina adaxial surface. 6. Lamina abaxial surface showing the sori. 7-8. Thelypteris interrupta (Willd.) K. Iwats. 7. Lamina adaxial surface. 8. Lamina abaxial surface showing the sori. (1-2: Ranal 1267, 3-4: Arantes \& Ranal 1406, 5-6: Ranal 948, 7-8: Ranal 981). 
Thelypteris subg. Cyclosorus (Link) C.V. Morton, Amer. Fern J. 53:153. 1963. $\equiv$ Cyclosorus Link, Hort. Berol. 2:128. 1833. $\equiv$ Dryopteris subg. Cyclosorus (Link) C. Chr., Index fil.:21. 1906. Tipo: Cyclosorus gongylodes (Schkuhr) Link [三 Aspidium gongylodes Schkuhr] = Thelypteris interrupta (Willd.) K. Iwats.

Rizoma reptante, decumbente ou ereto. Frondes 1-pinado-pinatífidas, pinas proximais reduzidas ou não; lâminas com aeróforos ou não, neste caso comumente com pequenas protuberâncias escuras no lugar dos aeróforos; nervuras livres, simples, com o par basal dos segmentos adjacentes livres, dirigindo-se para o sinus, coniventes logo abaixo deles ou unidas abaixo do sinus, formando uma vênula excurrente em direção ao sinus; indumento com tricomas aciculares, não ramificados, unicelulares, às vezes glandulares capitados, amarelados ou alaranjados, sobre costa, nervura, lâmina entre as nervuras e indúsio. Soros arredondados, indúsio reniforme; esporângios glabros ou com tricomas glandulares no pedicelo.

O subgênero Cyclosorus compreende 78 espécies, 18 delas ocorrentes no Novo Mundo (Mickel \& Smith 2004) e oito no Brasil (Salino \& Semir 2002).

A circunscrição do subgênero é baseada na combinação de alguns caracteres como nervuras basais dos segmentos adjacentes unidas abaixo do sinus ou livres, dirigindo-se coniventes para o sinus (figura 5), ausência de tricomas ramificados, lâminas pinado-pinatífidas, soros arredondados (figura 4), com indúsios persistentes e relativamente desenvolvidos e esporângios glabros. Smith \& Cranfill (2002) encontraram o subgênero Cyclosorus formando um clado fortemente sustentado não só por análises moleculares, como também morfológicas, baseadas na presença das nervuras unidas abaixo do sinus ou dirigindo-se para o mesmo.

A maioria das espécies do Novo Mundo possui rizoma rastejante. Isto é observado também para a área de estudo, onde somente Thelypteris hispidula possui rizoma ereto. Nas demais, os tipos de rizomas mais comuns variam entre rastejante e decumbente.

Na E.E. do Panga foi encontrado um possível híbrido entre Thelypteris dentata e T. hispidula com base em observações de esporos mal-formados de alguns espécimes. A hibridização é comum entre as espécies deste subgênero (Smith 1981, Mickel \& Smith 2004), especialmente entre as simpátricas. A presença de esporos mal-formados entre espécimes de herbário é uma das ferramentas úteis no estudo de híbridos. Neste caso, não foi possível determinar com exatidão o parentesco do possível híbrido, sem um completo estudo envolvendo as populações em campo e análise dos cromossomos. A completa discussão sobre o possível híbrido encontra-se nos comentários de T. dentata.

Chave para as espécies de Thelypteris subg. Cyclosorus da Estação Ecológica do Panga

1. Pinas com pares proximais de nervuras dos segmentos adjacentes livres, coniventes no sinus, logo abaixo do sinus, ou unidos abaixo do mesmo, formando uma vênula excurrente menor que $1 \mathrm{~mm}$ compr.; indúsios setosos, raro glabros, com tricomas glandulares .....

1. T. conspersa

1. Pinas com pares proximais de nervuras dos segmentos adjacentes sempre unidos abaixo do sinus, formando uma vênula excurrente maior que $1 \mathrm{~mm}$ compr.; indúsios setosos, com ou sem tricomas glandulares

2. Rizoma longo-reptante, pouco escamoso; face abaxial das pinas com escamas deltóides sobre a costa e cóstula; indúsios setosos, com tricomas glandulares

4. T. interrupta

2. Rizoma curto-reptante, decumbente ou ereto, castanho; face abaxial das pinas sem escamas; indúsios setosos, sem tricomas glandulares.

3. Rizoma ereto; face abaxial das pinas, especialmente sobre a costa e nervuras, densamente coberta por tricomas aciculares, a maioria com 0,3-0,6 mm compr.

3. T. hispidula

3. Rizoma curto-reptante ou decumbente; face abaxial das pinas, especialmente sobre a costa e nervuras, densamente coberta por tricomas aciculares, a maioria com $0,1-0,4$ mm compr. 2 .

T. dentata

1. Thelypteris conspersa (Schrad.) A. R. Sm., Univ. Calif. Publ. Bot. 59:60. 1971. 三 Nephrodium conspersum Schrad., Gött. Gel. Anz. 1824:869.1824. Lectótipo (designado por Smith, Univ. Calif. Publ. Bot. 59:60. 1971): BRASIL. Próximo ao Espírito Santo, Barra de Fucú, Wied-Neuwied s.n (isolectótipo BR, n.v.). = Dryopteris urens Rosenst., Repert. Spec. Nov. Regni Veg. 4:5. 1907. Tipo: URUGUAI. Punta Ballena, 1903,
Arechavaleta s.n. (holótipo S, n.v.; isótipo UC!). = Dryopteris patens (Sw.) Kuntze var. decrescens Rosenst., Hedwigia 46:114. 1907. Tipo: (lectótipo designado por Smith, Univ. Calif. Publ. Bot. 59:60. 1971): BRASIL. Santa Catarina: Blumenau, Haerchen 33 (S, n.v.). = Dryopteris bangii C.Chr., Kongel. Danske Vidensk. Selsk. Skr., Naturvidensk. Math. Afd., ser. 7, 4:333. 1907. $\equiv$ Lastrea bangii (C.Chr.) Copel., Gen. fil.:138. 
1947. $\equiv$ Cyclosorus bangii (C.Chr.) Abbiatti, Darwiniana 13:567. 1964. $\equiv$ Thelypteris bangii (C.Chr.) R.M. Tryon, Rhodora 69:5. 1967. Tipo: BOLÍVIA. Yungas, próximo a Coroico, A.M. Bang 2321 (holótipo C, n.v.).

= Cyclosorus hickenii Abbiatti, Darwiniana 13:537. 1964. $\equiv$ Thelypteris hickenii (Abbiatti) C. F. Reed, Phytologia 17:283. 1968. Tipo: ARGENTINA. ENTRE Ríos: Depto. Federación, Santa Ana, Río Uruguay, 24IX-1961, A. Burkart 22423 (holótipo S, n.v.).

Figuras 1-2

Rizoma reptante ou ereto, 0,5-1,5 cm diâm., com escamas 3-9 mm compr., lineares ou lanceoladas, brilhantes, castanho-claras, glabrescentes ou pubescentes. Frondes (25-)39-167 cm compr., subdimorfas, com as pinas férteis longo-pecioluladas e mais largas que as estéreis; pecíolos $10-47 \times 0,5-0,8 \mathrm{~cm}$, castanho-escuros ou castanhoesverdeados, opacos, densamente pubescentes; lâminas (15-)21-120 cm compr., herbáceas ou cartáceas, 2-3 pares de pinas proximais reduzidas, auriculadas na porção acroscópica proximal, ápice pinatífido; raque castanho-escura ou castanho-clara, densamente coberta por tricomas aciculares em ambas as faces; pinas $(3,5-)$ $5-14 \times 1,1-2,2 \mathrm{~cm}, 12-34$ pares, sésseis ou curto pecioluladas, profundamente pinatífidas a pinatissectas, incisão de $2 / 3$ da 4/5 da distância entre a costa e a margem da pina, ápice agudo, segmentos falcados a suboblíquos, nervuras 5-9 pares por segmento, os pares de nervuras proximais dos segmentos adjacentes livres, correndo em direção ao sinus, coniventes ou unidos abaixo dele, formando uma vênula excurrente com 0,5-0,8 mm compr.; indumento abaxial esparso a densamente piloso, especialmente sobre raque, costa, nervuras e lâmina entre as nervuras, com tricomas simples, setiformes, com 0,1-0,5 mm compr., e glandulares pedicelados, adaxialmente, com tricomas estrigosos esparsos, principalmente sobre cóstula e nervuras, dando um aspecto esbranquiçado à lâmina, tricomas glandulares, capitados e brilhantes sobre cóstula e nervuras. Soros medianos; indúsios setosos e com tricomas glandulares, raro glabros; esporângios com tricomas glandulares pedicelados.

Material examinado: BRASIL. Minas Gerais: Uberlândia, Estação Ecológica do Panga, III-1987, M.A. Ranal 404 (HUFU, SP); V-1987, M.A. Ranal 455 (HUFU, SP), 458 (HUFU, SP); V-1992, M.A. Ranal 587 (HUFU, SP, UC); XII-1998, M.A. Ranal 610 (HUFU, SP), 611 (HUFU, SP), 612 (HUFU, SP), 613 (HUFU); II-1999, M.A. Ranal 642 (HUFU, SP), 644 (HUFU), 645 (HUFU); I-2000, M.A. Ranal 1005 (HUFU, SP), 1011 (HUFU), 1013 (HUFU), 1016 (HUFU); IX-2004, A.A. Arantes \& M.A. Ranal 1243
(HUFU), 1256 (HUFU); X-2004, A.A. Arantes \& M.A. Ranal 1291 (HUFU), 1314 (HUFU), 1320 (HUFU), 1324 (HUFU), 1355 (HUFU); XII-2004, A.A. Arantes \& M.A. Ranal 1392 (HUFU), 1394 (HUFU), 1398 (HUFU), 1401 (HUFU), 1402 (HUFU), 1408 (HUFU).

Thelypteris conspersa é morfologicamente muito semelhante a $T$. dentata e $T$. hispidula, especialmente com relação ao padrão de nervuras. No entanto, o aspecto estrigoso do indumento adaxial em $T$. conspersa e a presença de tricomas glandulares no indúsio ajudam na distinção desta espécie. Thelypteris dentata e $T$. hispidula não possuem glândulas no indúsio.

A grande variabilidade das espécies de Cyclosorus na E.E. do Panga dificulta a rápida identificação e delimitação das mesmas. Thelypteris conspersa foi a espécie mais variável, com pelo menos três formas diferentes. A forma típica apresenta denso indumento abaxial formado por tricomas setiformes e, adaxialmente, por tricomas estrigosos (figura 2), além dos pares de nervuras proximais dos segmentos adjacentes serem livres em direção ao sinus ou coniventes logo abaixo dele (figura 1). Na segunda forma, o indumento é mais espaçado e glanduloso em ambas as faces que na forma típica, especialmente na lâmina entre as nervuras e sobre o indúsio; os pares de nervuras proximais dos segmentos adjacentes são, na maioria das vezes, livres. A terceira forma apresenta indumento semelhante ao da forma típica, mas os pares de nervuras proximais dos segmentos adjacentes podem variar desde livres, em direção ao sinus, coniventes abaixo do sinus a unidos abaixo dele, formando uma vênula excurrente, todos na mesma lâmina.

Thelypteris conspersa ocorre desde o Panamá até o nordeste da Argentina e Uruguai, com preferência por matas e campos, entre $400-1.300 \mathrm{~m}$ de altitude (Smith 1971). No Brasil, a espécie é amplamente distribuída, ocorrendo na Bahia, Mato Grosso, Mato Grosso do Sul, Goiás, Minas Gerais, São Paulo, Rio de Janeiro, Paraná, Santa Catarina e Rio Grande do Sul (Salino \& Semir 2002). Na E.E. do Panga foi coletada em mata de galeria e mata mesófila semidecídua de encosta, sempre próxima aos cursos d'água. A espécie também foi encontrada nessa mata, no banco de esporos do solo e de cascas de árvores (Ranal 2003, 2004).

2. Thelypteris dentata (Forssk.) E. P. St. John, Amer. Fern J. 26:44. 1936. 三 Polypodium dentatum Forssk., Fl. Aegypt.-Arab.:185. 1775. $\equiv$ Dryopteris dentata (Forssk.) C. Chr., Kongel. Danske Vidensk. Selsk. Skr., Naturvidensk. Math. Afd., VIII, 6:24. 1920. $\equiv$ Nephrodium dentatum (Forssk.) Kümm., Magyar. Bot. Lapok. 32:60. 
1933. $\equiv$ Cyclosorus dentatus (Forssk.) Ching, Bull. Fan Mem. Inst. Biol. 8:206. 1938. $\equiv$ Christella dentata (Forssk.) Brownsey \& Jermy, Brit. Fern Gaz. 10:338. 1973. Tipo. YEMEN. Forsskal s.n (holótipo C, n.v.). = Aspidium molle Sw., J. Bot. (Schrader) 1800 (2):34. 1801. $\equiv$ Dryopteris mollis (Sw.) Hieron., Hedwigia 46:348. 1907. Tipo. Espécime cultivado (isótipo W, n.v.).

Figuras 3-4

Rizoma rastejante ou decumbente, 0,5-1,2 cm diâm., com escamas 6-12 mm compr., linear-lanceoladas ou lanceoladas, brilhantes, castanho-escuras, glabras ou pubescentes nas margens. Frondes (21-)27-85 cm compr., subdimorfas, com as pinas férteis longo-pecioluladas e mais estreitas que as estéreis; pecíolos 7-39 x 0,2-0,7 $\mathrm{cm}$, castanho-escuros ou avermelhados, moderadamente pubescentes; lâminas 16-60 cm compr., herbáceas a cartáceas, 1-3 pares de pinas proximais reduzidas gradualmente, ápice pinatífido; pinas (4,5-)6-16 x 1,1-1,9 cm, 11-34 pares por lâmina, sésseis ou curto-pecioluladas, as basais auriculadas na porção acroscópica proximal, pinatífidas a pinatissectas, incisão de $1 / 2$ a $2 / 3$ da distância entre a costa e a margem da pina, ápice agudo ou cuspidado, segmentos retilíneos, suboblíquos; raque pilosa em ambas as faces, com tricomas aciculares; nervuras 6-10 pares por segmento, o par proximal de nervuras dos segmentos adjacentes unido abaixo do sinus, formando uma vênula excurrente com 1-3 mm compr.; indumento abaxial denso e uniforme, com tricomas aciculares curtos, a maioria com 0,1-0,4 mm compr., especialmente sobre a costa, nervuras e lâmina entre as nervuras, adaxialmente com tricomas aciculares sobre a cóstula, nervuras e lâmina entre as nervuras ou glabrescente. Soros medianos; indúsios setosos, sem tricomas glandulares; esporângios com tricomas glandulares no pedicelo.

Material examinado: BRASIL. Minas Gerais: Uberlândia, Estação Ecológica do Panga, III-1987, M.A. Ranal 403 (HUFU); IV-1999, M.A. Ranal 650 (HUFU), 657 (HUFU), 660 (HUFU), 668 (HUFU), 673 (HUFU, UC), 677 (HUFU), 687 (HUFU); IX-1999; M.A. Ranal 828 (HUFU), 829 (HUFU), 830 (HUFU), 831 (HUFU), 832 (HUFU), 836 (HUFU); X-1999, M.A. Ranal 859 (HUFU), 877 (HUFU), 910 (HUFU), 911 (HUFU); XI-1999, M.A. Ranal 933 (HUFU), 936 (HUFU), 945 (HUFU), 954 (HUFU), 963 (HUFU), 974 (HUFU); I-2000, M.A. Ranal 1018(HUFU); X-2004, A.A. Arantes \& M.A. Ranal 1357 (HUFU); XII-2004, A.A. Arantes \& M.A. Ranal 1389a (HUFU), $1389 b$ (HUFU), 1390 (HUFU), 1391 (HUFU), 1399 (HUFU), 1406 (HUFU), 1407 (HUFU), 1410 (HUFU).
De acordo com Smith (1992), Thelypteris dentata e T. hispidula são espécies muito semelhantes que, às vezes, podem formar híbridos. A grande semelhança entre as duas espécies deve-se ao fato delas apresentarem nervuras proximais dos segmentos adjacentes unidas abaixo do sinus, formando uma vênula excurrente (figura $3)$. No entanto, o indumento em $T$. dentata é formado por tricomas aciculares mais curtos e uniformes que em T. hispidula.

Prováveis espécimes híbridos entre Thelypteris dentata e T. hispidula foram encontrados na E.E. do Panga, com esporos mal-formados [Ranal 667 (HUFU) e Ranal 741 (HUFU)]. No entanto, são necessários estudos complementares para comprovar a natureza do híbrido e seus parentais.

Thelypteris dentata foi introduzida do Velho Mundo (trópicos e subtropicos), tornando-se amplamente naturalizada no Novo Mundo (Strother \& Smith 1970, Smith 1992, 1995), ocorrendo desde o sudeste dos E.U.A. até a Argentina (Ponce 1987, Smith 1992, 2000). No Brasil, é encontrada de Pernambuco ao Rio Grande do Sul, com preferência por locais mais iluminados e florestas secundárias, margens de estradas, trilhas, terrenos baldios e jardins, de 5-950 m de altitude (Salino \& Semir 2002). $\mathrm{Na}$ E. E. do Panga, T. dentata é comumente encontrada nas bordas e interiores das matas de galeria e mesófilas semidecíduas de encosta, e em áreas degradadas.

3. Thelypteris hispidula (Decne.) C. F. Reed, Phytologia 17:283. 1968. $\equiv$ Aspidium hispidulum Decne., Nouv. Ann. Mus. Hist. Nat. 3:346. 1834. $\equiv$ Christella hispidula (Decne.) Holttum, Kew Bull. 31:312. 1976. Tipo. TIMOR. Guichenot s.n. (P, n.v.).

= Nephrodium quadrangulare Fée, Mém. Foug. 5:308. 1852 . $\equiv$ Dryopteris quadrangularis (Fée) Alston, J. Bot. 75:253. 1937. $\equiv$ Thelypteris quadragularis (Fée) Schelpe, J. S. African Bot. 30:196. 1964. Tipo. GUIANA FRANCESA. Leprieur 182 (isótipos NY, n.v., P, n.v.).

Figuras 5-6

Rizoma ereto, 0,8-1,5 cm diâm., com escamas 3-6 mm compr., linear-lanceoladas, brilhantes, castanhas e pubescentes nas margens. Frondes 31-50 cm compr.; pecíolos 11-18(-22) x 0,3-0,4 cm, castanho-escuros, moderadamente pubescentes e com escamas apenas na porção basal, tornando-se glabrescentes e sem escamas na porção distal; lâminas $19-28 \mathrm{~cm}$ compr., herbáceas a cartáceas, 0-2 pares de pinas proximais gradualmente reduzidas, ápice gradualmente reduzido, pinatífido; raque densamente pubescente em ambas as faces; pinas 6-11 x 1,5-1,8 cm, 9-15 pares, sésseis ou curto-pecioluladas, pinatífidas a pinatissectas, incisão de 
1/2 a 2/3 da distância entre a costa e a margem da pina, ápice agudo ou cuspidado; segmentos retilíneos, suboblíquos ou subfalcados; nervuras 6-12 pares por segmento, par de nervuras proximais dos segmentos adjacentes unido abaixo do sinus, formando uma vênula excurrente com 1-2 mm compr.; indumento abaxial denso, formado por tricomas aciculares de tamanhos irregulares, a maioria com 0,3-0,6 mm compr., principalmente sobre a costa, nervuras e lâmina entre as nervuras, adaxialmente com tricomas aciculares sobre a costa, cóstula e nervuras. Soros medianos; indúsios setosos e sem tricomas glandulares; esporângios com tricomas glandulares nos pedicelos.

Material examinado: BRASIL. Minas Gerais: Uberlândia, Estação Ecológica do Panga, IV-1999, M.A. Ranal 653 (HUFU), 661 (HUFU), 662 (HUFU), 680 (HUFU), 681 (HUFU, SP); V-1999, M.A. Ranal 697 (HUFU), 716 (HUFU); IX-1999, M.A. Ranal 847 (HUFU); X-1999, M.A. Ranal 903 (HUFU); XI-1999, M.A. Ranal 948 (HUFU).

Thelypteris hispidula e T. dentata são muito semelhantes. Thelypteris hispidula difere de T. dentata pelo rizoma ereto, pelo indumento abaxial com tricomas de tamanhos irregulares e maiores, e também pela preferência por locais sombreados e não perturbados. Por outro lado, $T$. dentata tende a apresentar pecíolo e raque com coloração mais avermelhada, além da sua preferência por ambientes mais iluminados e/ou com algum grau de distúrbio.

Thelypteris hispidula é amplamente distribuída desde o sudeste dos E.U.A. até o nordeste da Argentina e Uruguai. No Velho Mundo ocorre na África tropical e subtropical e Ásia (Smith 1995). No Brasil foi coletada do Amazonas até o Rio Grande do Sul (Salino \& Semir 2002). Na E. E. do Panga a espécie é restrita a uma pequena população no interior da mata de galeria.

4. Thelypteris interrupta (Willd.) K. Iwats., Jap. J. Bot. 38:314. 1963. $\equiv$ Pteris interrupta Willd., Phytogr.:13, tab.10, fig. I. 1794. $\equiv$ Cyclosorus interruptus (Willd.) H. Itô, Bot. Mag. Tokyo 51:714. 1937. Tipo: ÍNDIA. Klein s.n. (B-Willd. 19770, n.v.).

= Polypodium tottum Thunb., Prodr. Fl. Cap.:172. 1800. $\equiv$ Thelypteris totta (Thunb.) Schelpe, J. S. African Bot. 29:91. 1963. $\equiv$ Cyclosorus tottus (Thunb.) Pic. Serm., Webbia 23:173. 1968. Tipo: ÁFRICA DO SUL. Thunberg Hb. 24724 (UPS, n.v.).

= Aspidium gongylodes Schkuhr, Vier Zwan. Kl. Linn. Pfl. Krypto. Gew. 1:193, t.33c. 1809. $\equiv$ Cyclosorus gongylodes (Schkuhr) Link, Hort. Berol. 2:128. 1833. $\equiv$ Thelypteris gongylodes (Schkuhr) Small, Ferns S.E. States:248. 1938. Tipo: GUIANA. Essequibo, recebido por Gärtner (isótipos B, n.v., S, n.v.).
Figuras 7-8

Rizoma longo-reptante, $0,4-0,5$ cm diâm., com poucas escamas 1-2,5 mm compr., lanceoladas, castanhas e glabras. Frondes 47-110 cm compr.; pecíolo 16-48 x 0,2$0,4 \mathrm{~cm}$, escuro na porção basal e paleáceo distalmente, com poucas escamas, glabrescente; lâminas $25-58 \mathrm{~cm}$ compr., cartáceas a subcoriáceas, pinas 5,5-17 x 1,1-1,9 cm compr., as distais gradualmente reduzidas e ápice pinatífido ou abruptamente reduzido; raque glabra ou pubescente nas duas faces; pinas 13-15(-20) pares, curtopecioluladas, 1-3 mm compr., pinatilobadas, lineares ou oblongo-lanceoladas, base truncada, ápice agudo, incisão de $1 / 3$ da distância entre a costa e a margem da pina, segmentos deltóides, margens ciliadas; nervuras de 5-10 pares por segmento, o par proximal de nervuras dos segmentos adjacentes unido abaixo do sinus, formando um ângulo obtuso e uma vênula excurrente com 2-4,5 mm compr.; lâminas glabras ou pubescentes abaxialmente, freqüentemente com escamas deltóides e castanhas, 0,31,2 mm compr., sobre costa e cóstula. Soros medianos a supramedianos, às vezes confluentes na maturidade; indúsios glabros a setosos, com tricomas glandulares; esporângios com tricomas glandulares avermelhados no pedicelo.

Material examinado: BRASIL. Minas Gerais: Uberlândia, Estação Ecológica do Panga, III-1999, J. Prado \& M.A.Ranal 1012 (HUFU); XII-1999, M.A. Ranal 990 (HUFU); Parque do Sabiá, XI-1999, M.A. Ranal 981 (HUFU, UC).

O indumento em Thelypteris interrupta pode variar de glabro a densamente piloso. Os dois exemplares examinados da E.E. Panga eram completamente glabros, mas em outros materiais examinados de áreas próximas ao local de estudo, os espécimes apresentavam tricomas aciculares em ambas as faces das lâminas.

A espécie é facilmente distinguida das demais pelo rizoma longamente rastejante e negro, presença de escamas sobre a costa (figura 8), e pinas com as margens lobadas.

Dados de ocorrência desta espécie são apresentados por Smith (1992, 1995), Salino \& Semir (2002), Mickel \& Smith (2004), sendo encontrada desde a Flórida (E.U.A.), México, Antilhas, da América Central ao nordeste da Argentina e Uruguai. No Velho Mundo ocorre nas regiões tropicais e subtropicais. No Brasil é amplamente distribuída do Amazonas ao Rio Grande do Sul, crescendo em locais alagados. Na E. E. do Panga foi coletada na mata de galeria, em barrancos das margens do Ribeirão Panga, e em veredas.

Agradecimentos - os autores agradecem ao Dr. Alan R. Smith pela ajuda na identificação das espécies estudadas e pela agradável recepção à primeira autora durante sua visita ao Herbário da Universidade de Califórnia (UC), e ao Instituto de Biologia da UFU pelo apoio a esta pesquisa. 


\section{Referências bibliográficas}

ARANTES, A.A. 2002. Florística, fitossociologia e fenologia do estrato herbáceo-arbustivo de um gradiente florestal no Triângulo Mineiro, Minas Gerais, Brasil. Tese de doutorado, Universidade Estadual Paulista, Rio Claro, SP.

ARANTES, A.A., RANAL, M.A. \& PRADO, J. 2007. Thelypteris subg. Goniopteris e Meniscium (Thelypteridaceae) da Estação Ecológica do Panga, Uberlândia, Minas Gerais, Brasil. Hoehnea 34:121-129.

ARAÚJO, G.M., BARBOSA, A.A.A., ARANTES, A.A. \& AMARAL, A.F. 2002. Composição florística de veredas no Município de Uberlândia, MG. Revista Brasileira de Botânica 25:475-493.

BAKER, J.G. 1870. Cyatheaceae et Polypodiaceae. In Flora brasiliensis (C.F.P. Martius \& A.G. Eichler, eds.). F. Fleischer, Lipsiae, v.1, p.306-624.

CARDOSO, E. \& SCHIAVINI, I. 2002. Relação entre distribuição de espécies arbóreas e topografia em um gradiente florestal na Estação Ecológica do Panga (Uberlândia, MG). Revista Brasileira de Botânica 25:277-289.

DRUMMOND, G.M., MARTINS, C.S., MACHADO, A.B.M., SEBAIO, F.A. \& ANTONINI, Y. (orgs.). 2005. Biodiversidade em Minas Gerais: um atlas para sua conservação. 2ª ed. Fundação Biodiversitas, Belo Horizonte.

MAXON, W.R. \& MORTON, C.V. 1938. The American species of Dryopteris, subgenus Meniscium. Bulletin of the Torrey Botanical Club 65:347-376.

MICKEL, J.T. \& SMITH, A.R. 2004. Pteridophytes of Mexico. Memoirs of the New York Botanical Garden 88:1-1070.

PICHI SERMOLLI, R.E.G. 1996. Authors of scientific names in Pteridophyta. Royal Botanical Gardens, Kew.

PONCE, M.M. 1987. Revisión de las Thelypteridaceae (Pteridophyta) argentinas. Darwiniana 28:317-390.

PONCE, M.M. 1995. Las especies austrobrasileñas de Thelypteris subg. Amauropelta (Thelypteridaceae, Pteridofita). Darwiniana 33:257-283.

RANAL, M.A. 2003. Soil spore bank of ferns in a gallery forest of the Ecological Station of Panga, Uberlândia, MG, Brazil. American Fern Journal 93:97-115.

RANAL, M.A. 2004. Bark spore bank of ferns in a gallery forest of the Ecological Station of Panga, Uberlândia, MG, Brazil. American Fern Journal 94:57-69.
SALINO, A. \& SEMIR, J. 2002. Thelypteridaceae (Polypodiophyta) do Estado de São Paulo: Macrothelypteris e Thelypteris subgêneros Cyclosorus e Steiropteris. Lundiana 3:9-27.

SALINO, A. \& SEMIR, J. 2003. Notas sobre duas espécies de Thelypteris Schmidel (Thelypteridaceae - Pterophyta) do Brasil. Acta Botanica Brasilica 17:515-523.

SALINO, A. \& SEMIR, J. 2004a. Thelypteris subg. Meniscium (Thelypteridaceae-Pterophyta) no Estado de São Paulo, Brasil. Revista Brasileira de Botânica 27:103-114.

SALINO, A. \& SEMIR, J. 2004b. Thelypteris subg. Amauropelta (Kunze) A.R. Sm. (Thelypteridaceae - Pterophyta) no Estado de São Paulo. Lundiana 5:83-112.

SCHIAVINI, I. \& ARAÚJO, G.M. 1989. Considerações sobre a vegetação da Reserva Ecológica do Panga (Uberlândia). Sociedade \& Natureza, Uberlândia 1:61-66.

SEHNEM, A. 1979. Aspidiáceas. In Flora Ilustrada Catarinense (R. Reitz, ed.). Herbário Barbosa Rodrigues, Itajaí, p.1-360.

SMITH, A.R. 1971. Systematics of the neotropical species of Thelypteris section Cyclosorus. University of California Publications in Botany 59:1-143.

SMITH, A.R. 1981. Pteridophytes. In Flora of Chiapas (D.E. Breedlove, ed.). California Academy of Sciences, San Francisco, v.2, p.1-370.

SMITH, A.R. 1990. Thelypteridaceae. In The families and genera of vascular plants (K.U. Kramer \& P.S. Green, eds.). Pteridophytes and Gymnosperms. Springer-Verlag, Berlin, v.1, p.263-272.

SMITH, A.R. 1992. Thelypteridaceae. In Pteridophyta of Peru, Part III. (R.M. Tryon \& R.G. Stolze, eds.). Fieldiana Botany, New Series, v.29, p.1-80.

SMITH, A.R. 1995. Pteridophytes. In Flora of the Venezuelan Guayana (J. A. Steyermark, P. E. Berry \& B. K. Holst, eds.). Timber Press, Portland, v.2, p.1-334.

SMITH, A.R. 2000. Pteridophyta. In Catalogue of the vascular plants of Guaramacal National Park, Portuguesa and Trujillo States, Venezuela (L.J. Dorr, B. Stergios, A.R. Smith \& N.L. Cuello A., eds.). Contributions from the United States National Herbarium 40:1-155.

SMITH, A.R. \& CRANFILL, R.B. 2002. Intrafamilial relationships of the thelypteroid ferns (Thelypteridaceae). American Fern Journal 92:131-149.

STROTHER, J.L. \& SMITH, A.R. 1970. Chronology, collection dates, and taxonomic responsibility. Taxon 19:871-874. 